\title{
Investigating the relationship between dietary acid load and risk of diabetes; a meta-analysis
}

\author{
Mozhgan Ghorbani $^{\circledR}$, Nasrin Moradi², Bahareh Behzadi ${ }^{\circledR}$, Toran Shahani ${ }^{\circledR}$, Masoumeh Sadat Mousavi ${ }^{5,6^{*}(\mathbb{D},}$ \\ Saeid Fathi ${ }^{7}$
}

${ }^{1}$ School of Health, Shahrekord University of Medical Sciences, Shahrekord, Iran

${ }^{2}$ PhD Student, School of Medical Management and information, Iran University of Medical Sciences, Tehran, Iran

${ }^{3}$ Department of Epidemiology and Biostatistics, Medical School, Rafsanjan University of Medical Sciences, Rafsanjan, Iran

${ }^{4}$ Department of Virology, School of Medicine, Ahvaz Jundishapur University of Medical Sciences, Ahvaz, Iran

${ }^{5}$ Modeling in Health Research Center, Shahrekord University of Medical Sciences, Shahrekord, Iran

${ }^{6}$ Department of Epidemiology and Biostatistics, School of Public Health, Shahrekord University of Medical Sciences, Shahrekord, Iran

${ }^{7}$ Deputy of Health, Shahrekord University of Medical Sciences, Shahrekord, Iran Shahrekord, Iran

\section{Correspondence to: \\ Masoumeh Sadat Mousavi, Email: mousavi68.ma@yahoo. com,ma@skuns.ac.ir}

Received: 14 Feb. 2021 Accepted: 16 June 2021 ePublished: 20 Aug. 2021

Keywords: Meta-analysis, Diabetes, Dietary acid load

\begin{abstract}
Citation: Ghorbani M, Moradi N, Behzadi B, Shahani T, Masoumeh Sadat Mousavi MS Fathi S. Investigating the relationship between dietary acid load and risk of diabetes; a metaanalysis. J Prev Epidemiol 2021;6(1):e16. doi: 10.34172/jpe.2021.16
\end{abstract}

\begin{abstract}
Introduction: Diabetes is the most common endocrine disease that annually causes four million deaths in the world. It is not just a disease, however a series of metabolic disorders caused by defects in insulin secretion, insulin action, or both. Considering the importance of diet in the incidence and complications of diabetes, this study aimed to investigate the relationship between the dietary acid load with diabetes, which has recently been considered.

Methods: This meta-analysis was first performed as a systematic review by searching in Google Scholar, Science Direct, PubMed, Wiley, Directory of Open Access Journals (DOAJ), Springer, Cochrane, ProQuest, and Scopus, as well as domestic databases including Magiran, SID, Irandoc, and Google Scholar. A total of 1511 articles were found that after reviewing and excluding irrelevant articles, five were included in the study.

Results: In the present study, a significantly high heterogeneity was observed $(I 2=61.5, P=0.01)$. A randomeffect model was used and the studies were weighted using the inverse-variance method. The odds ratio (OR) obtained from the meta-analysis was 1.17 (1.12-1.22). Examination of publication bias showed that the studies were symmetrically distributed in the funnel plot. Egger's and Begg's tests were also performed that showed no evidence for the existence of publication bias [Egger's test $(P \geq 0.79)$ and Begg's test $(P \geq 0.69)$ ].

Conclusion: The results of the present meta-analysis showed a significant relationship between dietary acid load and the incidence of diabetes. This result is similar to most studies on the subject, except for one study, which was limited to the elderly male population. The number of studies in the present meta-analysis was low due to the limited number of research in this field.
\end{abstract}

\section{Introduction}

Statement of the problem and the importance of the subject

Diabetes is the most common endocrine disease that annually causes four million deaths in the world (1). It is not just a disease, however a series of metabolic disorders caused by defects in insulin secretion, insulin action, or both (2). The World Health Organization (WHO) has identified diabetes as a latent epidemic due to rising statistics and upward trends. In 2010, the global prevalence of diabetes among adults was $6.4 \%$ i.e. about 285 million people. In 2012, it increased to 371 million cases, and it is predicted that by 2030 , it will reach about 552 million people $(3,4)$. It is one of the most common non-communicable diseases in the world and one of the ten leading causes of death in many countries

\section{Key point}

The results of our meta-analysis showed a significant relationship between dietary acid load and the incidence of diabetes.

(5). A study published in 2010 stated that by 2030 , the prevalence of diabetes in the Middle East will significantly increase and it is estimated that its annual growth rate will reach the second ranking in the Middle East after Pakistan by 2030 (1). In terms of importance, diabetes mellitus is the main cause of blindness among people aged 2575 and the leading cause of amputation in the United States. Moreover, 25\% of people with chronic kidney failure and dialysis are diabetics (5). Complications of diabetes affect almost all organs of the body. The higher the prevalence of this disease, the higher its 
costs, including diagnosis, treatment, and complications. People with diagnosed diabetes have medical expenditures approximately 2.3 times higher than what expenditures would be in the absence of diabetes (6). The incidence of type 2 diabetes depends on environmental and genetic factors. Most preventive measures focus on the modification of environmental factors such as weight gain, inactivity, perinatal complications, and diet (7). Considering the importance of diet in the incidence of diabetes and its complications, in this study, we investigated the relationship between one of the dietary factors called dietary acid load and diabetes that has recently been considered.

Mild metabolic acidosis caused by diet may increase cortisol and calcium excretion, and decrease citrate excretion, which may cause obesity and increased cholesterol (8). Acidogenic diet is associated with increased hydrogen ion load and the production of nonvolatile acids such as $\mathrm{HCl}$ and $\mathrm{H}_{2} \mathrm{SO}_{4}$ in the body, which are excreted by compensatory processes through the lungs and kidneys (9). If the production of these acids exceeds the body's excretory capacity, it can cause metabolic acidosis. This condition may occur due to the consumption of high-protein diets and inadequate consumption of fruits and vegetables rich in cations and bicarbonate, which have an alkaline effect. Due to the high animal protein content (e.g. red meat, meat products, eggs) and processed foods (e.g. energy drinks) the Western diet has attracted much attention in terms of its effect on the body's basic acid balance (10). Dietary acid load has recently been suggested as a risk factor for cardiovascular diseases, metabolic disorders, high blood pressure, high blood sugar, and low blood insulin.

\section{Objectives}

Few studies have examined the association between dietary acid load and non-communicable diseases, some of which have conflicting results. Thus, in this study, we aimed to evaluate the relationship between dietary acid load and diabetes.

\section{Methods}

This was a systematic review and meta-analysis. The statistical population included all studies published on the relationship between dietary acid load and the incidence of diabetes.

\section{Inclusion criteria}

1. General population over 20 years of age.

2. Having type 2 diabetes

3. An estimate of the relative risk or hazard ratio and $95 \%$ confidence interval corresponding to type 2 diabetes and dietary acid load.

\section{A: Strategy to search for Persian resources}

To study Persian sources, dietary acid load and diabetes keywords were searched in Magiran, SID, Irandoc, and Google Scholar databases.

\section{B: Strategy to search for English resources}

To check English resources, Google Scholar, Science Direct, PubMed, Wiley, Directory of Open Access Journals (DOAJ), Springer, Cochrane, ProQuest, and Scopus databases, with the keywords dietary acid Load, acid-base imbalance, acid-base, acid load, diabetes mellitus, type 2 diabetes, and diabetes were searched.

The total number of articles obtained from the databases was 1511,1413 of which were excluded after reviewing the abstracts and titles and 98 entered the second stage of screening. The exclusion criterion at this stage was the duplication of articles, so, 82 articles were excluded. Of the remaining 17 articles, 12 were excluded due to inconsistency of the text with the study objectives and completion of the STROBE checklist, and finally, five studies with a Strobe checklist score above eight remained for the study (Figure 1).

After reviewing and evaluating the quality of the articles during a systematic review, five articles were selected for final analysis, all of which were in English. Information on selected articles is shown in Table 1. The full text of the selected articles was reviewed and the following data were extracted: Name of the first author, year of publication, title, country, duration of follow-up, mean age and number of participants, dietary acid load indices, diet evaluation method, criteria for diagnosis of type 2 diabetes, quantitatively adjusted variables, and risk assessment. Of these articles, three showed a significant relationship between dietary acid load and the incidence of diabetes, one reported only a significant relationship between dietary acid load and the incidence of diabetes in men, and one showed no significant relationship.

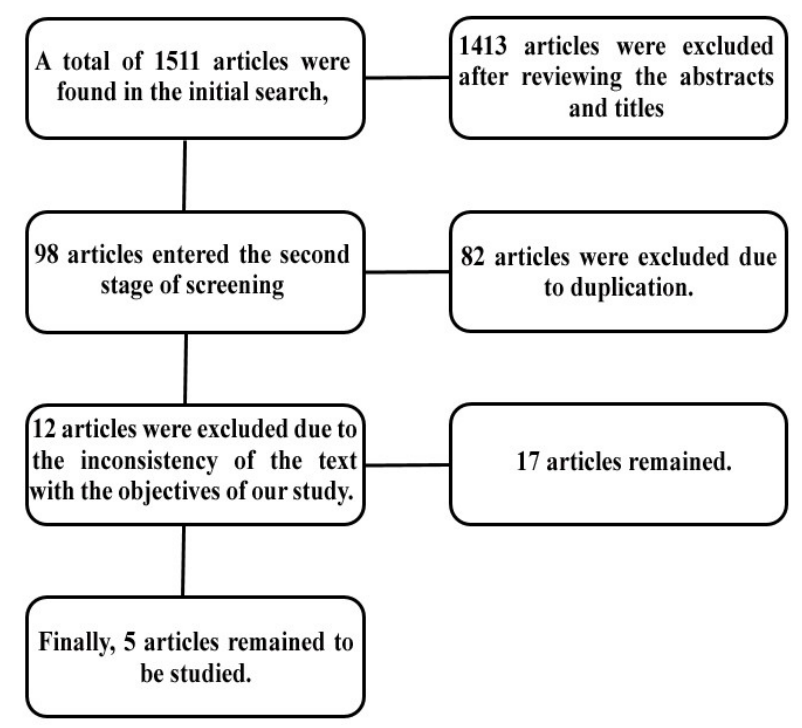

Figure 1. Steps for including articles in the systematic review and metaanalysis. 
Table 1. Details of articles reviewed on the relationship between acid load and the incidence of diabetes

\begin{tabular}{|c|c|c|c|c|c|c|c|c|c|c|c|}
\hline Author & Country & $\begin{array}{l}\text { Follow-up } \\
\text { Duration (year) }\end{array}$ & $\begin{array}{l}\text { Participants/ } \\
\text { Case (year) }\end{array}$ & Gender & $\begin{array}{l}\text { Mean age } \\
\text { (year) }\end{array}$ & Exposure & $\begin{array}{l}\text { Exposure } \\
\text { assessment }\end{array}$ & Outcome & $\begin{array}{l}\text { OR } \\
\text { HR }\end{array}$ & $\begin{array}{l}\text { Outcome } \\
\text { assessment }\end{array}$ & $\begin{array}{l}\text { Quality } \\
\text { score }\end{array}$ \\
\hline Xu et a $\mathbf{l}^{17}$ & Sweden & 18 & $911 / 115$ & M & 50 older & $\begin{array}{l}\text { PRAL } \\
\text { NEAP }\end{array}$ & $\begin{array}{l}7 \text { day dietary } \\
\text { record }\end{array}$ & $\begin{array}{l}\text { Incident type } 2 \\
\text { diabetes }\end{array}$ & $\mathrm{OR}=0.84$ (for PRAL) & FBS & 8 \\
\hline Fagherazzi et al ${ }^{13}$ & France & 14 & $66485 / 1372$ & w & $52.6 \pm 6.4$ & $\begin{array}{l}\text { PRAL } \\
\text { NEAP }\end{array}$ & $\begin{array}{l}\text { Validated 208- } \\
\text { item diet-history } \\
\text { questionnaire }\end{array}$ & $\begin{array}{l}\text { Incident type } 2 \\
\text { diabetes }\end{array}$ & $\mathrm{HR}=1.56$ (for PRAL) & $\begin{array}{l}\text { Validated } \\
\text { self-reported } \\
\text { diabetes }\end{array}$ & 9 \\
\hline Akter et al ${ }^{12}$ & Japan & 5 & $64660 / 1191$ & $\begin{array}{l}M \\
W\end{array}$ & $45-75$ & $\begin{array}{l}\text { PRAL } \\
\text { NEAP }\end{array}$ & FFQ & $\begin{array}{l}\text { Incident type } 2 \\
\text { diabetes }\end{array}$ & $\mathrm{OR}=1.25$ (for PRAL) & $\begin{array}{l}\text { Validated self- } \\
\text { reported }\end{array}$ & 8 \\
\hline $\begin{array}{l}\text { Kiefte-de Jong } \\
\text { et } \mathrm{al}^{14}\end{array}$ & USA & $\begin{array}{l}25 \\
18 \\
22\end{array}$ & $\begin{array}{l}67433 / 7655 \\
84310 / 4109 \\
35743 / 3541\end{array}$ & $\begin{array}{l}\text { W } \\
W \\
M\end{array}$ & $\begin{array}{l}30-55 \\
25-42 \\
40-75\end{array}$ & $\begin{array}{l}\text { PRAL } \\
\text { NEAP } \\
\text { Pro:K }\end{array}$ & FFQ & $\begin{array}{l}\text { Incident type } 2 \\
\text { diabetes }\end{array}$ & $\begin{array}{l}\mathrm{HR}=1.29(\text { for NEAP and PRAL }) \\
\mathrm{HR}=1.39(\text { for Pro: } \mathrm{K})\end{array}$ & $\begin{array}{l}\text { Validated self- } \\
\text { reported }\end{array}$ & 9 \\
\hline Gæde et $\mathrm{al}^{18}$ & Denmark & 15 & $56479 / 7201$ & $\begin{array}{l}M \\
W\end{array}$ & $50-64$ & $\begin{array}{l}\text { PRAL } \\
\text { NEAP }\end{array}$ & FFQ & $\begin{array}{l}\text { Incident type } 2 \\
\text { diabetes }\end{array}$ & $H R=1.24(1.14-1.35)$ & $\begin{array}{l}\text { Validated self- } \\
\text { reported }\end{array}$ & 8 \\
\hline
\end{tabular}

PRAL, potential renal acid load; NEAP, Net endogenous acid production; FFQ, Food Frequency Questionnaire; HR, hazard ratio. 
Dietary acid load is calculated using the following two methods (11).

1. The PRAL (potential renal acid load), which is calculated by estimation of the intestinal absorption of five nutrients including protein, potassium, phosphorus, magnesium, and calcium:

PRAL $(\mathrm{mEq} / \mathrm{d})=($ protein $[\mathrm{g} / \mathrm{d}] \times 0.49)(\mathrm{P}[\mathrm{mg} / \mathrm{d}] \times 0.37)$ - $(\mathrm{K}[\mathrm{mg} / \mathrm{d}] \times 0.021)-(\mathrm{Ca}[\mathrm{mg} / \mathrm{d}] \times 0.013)-(\mathrm{mg}[\mathrm{mg} / \mathrm{d}]$ $\times 0.026$ )

2. Net endogenous acid production (NEAP), which is calculated as follows:

$\operatorname{NEAP}(\mathrm{mEq} /$ day $)=(54.5 \times$ protein $[\mathrm{g} /$ day $] /$ potassium $[\mathrm{mEq} /$ day $])-10.2$

\section{Results}

The total number of subjects was 376021, of whom 25185 were reported to be diabetic during the follow-up period. The participants' age range was over 25 years. In this study, heterogeneity was significantly high $\left(\mathrm{I}^{2}=61.5, P=0.01\right)$. The $\mathrm{l}^{2}$ index is used to check the percentage of heterogeneity and if it is above $50 \%$, it indicates heterogeneity, hence the random effects model shall be used. In this study, the random effects model was used and the weighting was performed by the inverse-variance method. In this model, it is assumed that the observed differences are due to different sampling and also the difference in the parameter measured in the studies. Figure 2 shows the overall and separate odds ratio of all studies based on the random effects model. Dashed lines show the distance between the odds ratio of diabetes in each study. The odds ratio obtained from the meta-analysis of the studies is $\mathrm{OR}=1.17$ (1.12-1.22), which indicates the relationship between dietary acid load and diabetes. Evaluation of publication bias showed that the studies have no bias and are shown symmetrically in the funnel plot (Figure 3). Egger's and Begg's tests were also performed and showed no publication bias (Egger's test, $P \geq 0.79$; and Begg's test, $P \geq 0.69)$.

\section{Discussion}

This meta-analysis reviewed the literature on the potential renal acid load index, which is associated with the dietary acid load, and its relationship with the incidence of type 2 diabetes. Of the studies reviewed, three were from the United States (14), three from Europe (16-18), and one from Asia (19).

Regarding data collection tools, four studies had used a validated food frequency questionnaire to assess food intake $(13,14,16,18)$, while one study had used a 7 -day dietary record (17). All studies were high-quality prospective cohorts (8 points). In this study, the acid load calculated by the PRAL method was evaluated and indicated the excretion of pure renal acid due to the consumption of one of the food components or the whole $\operatorname{diet}(20)$.

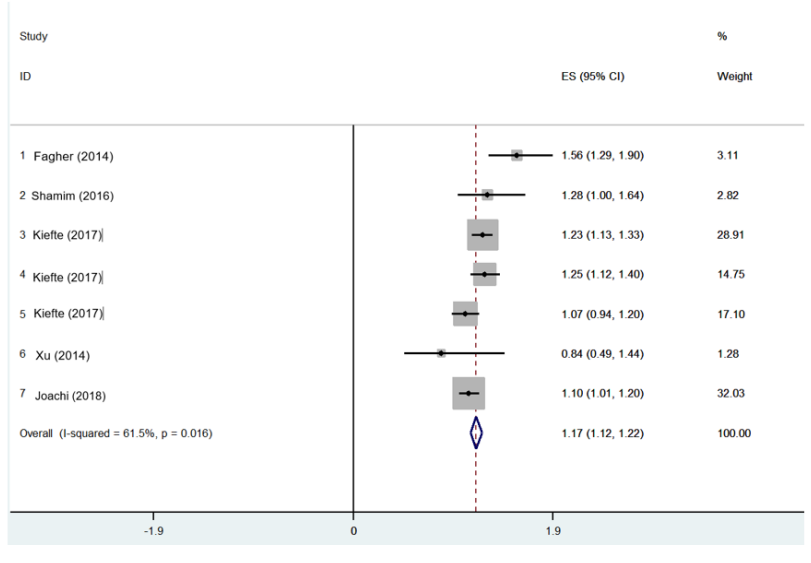

Figure 2. Forest Plot for the odds ratio of the relationship between dietary acid load and the incidence of diabetes.

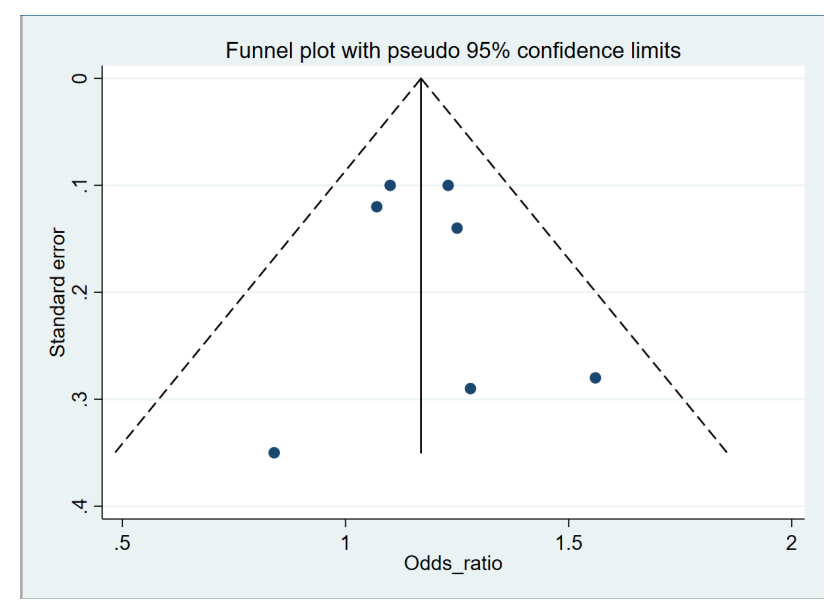

Figure 3. Publication bias for the relationship between dietary acid load and the incidence of diabetes.

The results of this study showed that people with higher levels of dietary acid load are 17\% more likely to develop diabetes. From the studies included in the meta-analysis, four had reported results similar to our study, and one study in Uppsala had reported results contrary to our results, which may be due to the type of population selected in this study (only elderly men). In the study by Fagherazzi et al, a significant relationship was found between dietary acid load and the incidence of diabetes, therefore people with high quartiles of dietary acid load are 56\% more likely to develop diabetes (13). Akter et al also performed a study on men in Japan and showed that people with high quartiles of acid load are 58\% more likely to develop diabetes than the control group (21). Kiefte-de Jong et al, combined the results of three prospective cohort studies, found that people with high levels of dietary acid intake are $20 \%$ more likely to develop diabetes (14). Gædeet al in Denmark found that people with high levels of dietary acid intake are $24 \%$ more likely to develop diabetes (18). However, $\mathrm{Xu}$ et al reported no significant relationship between dietary acid load and the incidence of diabetes (17). 


\section{Strengths of the study}

The main strength of the present study is that the evaluated studies included several prospective cohorts with a large sample size and a long follow-up period. The other strength was using a checklist and selection of studies with high scores.

\section{Weaknesses of the study}

The number of studies was very small to review the analyses in several subgroups. The number of studies obtained after a systematic review was five. Moreover, the number of female participants was significantly higher than male, and some studies were limited to specific occupations.

\section{Recommendations}

There is a need for intervention studies to assess whether changes in dietary acid load affect the body's acid-base balance and the risk of chronic diseases.

\section{Conclusion}

The results indicated that following a diet with a high acid load may be associated with an increased risk of type 2 diabetes.

\section{Authors' contribution}

MG, MSM and SF, all participated in research of articles and statistical analysis. MSM additionally conducted the final edit. All authors read and signed the final paper.

Conflicts of interest

The authors declare that they have no competing interests.

\section{Ethical considerations}

The institutional ethical committee of Shahrekord University of Medical Sciences approved all study protocols (Ethical code\#IR. SKUMS.REC.1399.225). This study was extracted from the MSc thesis of Mozhgan Ghorbani at this university (Thesis\#5519). Additionally, Ethical issues (including plagiarism, data fabrication, double publication) have been completely observed by the authors.

\section{Funding/Support}

None.

\section{References}

1. Olfatifar M, Karami M, Shokri P, Hosseini SM. Prevalence of Chronic Complications and Related Risk Factors of Diabetes in Patients Referred to the Diabetes Center of Hamedan Province. Avicenna J Nurs Midwifery Care. 2017;25(2):69-74. doi: 10.21859/nmj-25029.

2. Association AD. Diagnosis and classification of diabetes mellitus. Diabetes care. 2009;32(Supplement 1):S62-S7.

3. Gupta S, Hrishikeshvan HJ, Sehajpal PK. Spirulina protects against rosiglitazone induced osteoporosis in insulin resistance rats. Diabetes Res Clin Pract. 2010;87:38-43. doi: 10.1016/j. diabres.2009.10.002.

4. Guariguata L. By the numbers: new estimates from the IDF Diabetes Atlas Update for 2012. Diabetes Res Clin Pract. 2012;98:524-5. doi: 10.1016/j.diabres.2012.11.006.

5. CDC. National diabetes fact sheet. http://www.cdc.gov/ diabetes/pubs/pdf/ndfs_2011.pdf. 2011.

6. Seuring $T$, Archangelidi O, Suhrcke M. The Economic
Costs of Type 2 Diabetes: A Global Systematic Review. Pharmacoeconomics. 2015;33:811-31. doi: 10.1007/s40273015-0268-9.

7. Hussain A, Claussen B, Ramachandran A, Williams R. Prevention of type 2 diabetes: a review. Diabetes Res Clin Pract. 2007;76:317-26. doi: 10.1016/j.diabres.2006.09.020.

8. Murakami K, Sasaki S, Takahashi Y, Uenishi K; Japan Dietetic Students' Study for Nutrition and Biomarkers Group. Association between dietary acid-base load and cardiometabolic risk factors in young Japanese women. $\mathrm{Br} J$ Nutr. 2008;100:642-51. doi: 10.1017/S0007114508901288.

9. Williams RS, Heilbronn LK, Chen DL, Coster AC, Greenfield JR, Samocha-Bonet D. Dietary acid load, metabolic acidosis and insulin resistance - Lessons from cross-sectional and overfeeding studies in humans. Clin Nutr. 2016;35:1084-90. doi: 10.1016/j.clnu.2015.08.002.

10. Fung TT, Schulze M, Manson JE, Willett WC, Hu FB. Dietary patterns, meat intake, and the risk of type 2 diabetes in women. Arch Intern Med. 2004;164:2235-40. doi: 10.1001/ archinte.164.20.2235.

11. Bahadoran Z, Mirmiran P, Khosravi H, Azizi F. Associations between Dietary Acid-Base Load and Cardiometabolic Risk Factors in Adults: The Tehran Lipid and Glucose Study. Endocrinol Metab (Seoul). 2015;30:201-7. doi: 10.3803/ EnM.2015.30.2.201

12. Akter S, Eguchi M, Kurotani K, Kochi T, Pham NM, Ito R, et al. High dietary acid load is associated with increased prevalence of hypertension: the Furukawa Nutrition and Health Study. Nutrition. 2015;31:298-303. doi: 10.1016/j.nut.2014.07.007.

13. Fagherazzi G, Vilier A, Bonnet F, Lajous M, Balkau B, BoutronRualt $\mathrm{MC}$, et al. Dietary acid load and risk of type 2 diabetes: the E3N-EPIC cohort study. Diabetologia. 2014;57:313-20. doi: 10.1007/s00125-013-3100-0.

14. Kiefte-de Jong JC, Li Y, Chen M, Curhan GC, Mattei J, et al. Diet-dependent acid load and type 2 diabetes: pooled results from three prospective cohort studies. Diabetologia. 2017;60:270-279. doi: 10.1007/s00125-016-4153-7.

15. Xu H, Åkesson A, Orsini N, Håkansson N, Wolk A, Carrero JJ. Modest U-Shaped Association between Dietary Acid Load and Risk of All-Cause and Cardiovascular Mortality in Adults. Nutr. 2016;146:1580-5. doi: 10.3945/jn.116.231019.

16. Han E, Kim G, Hong N, Lee $Y H$, Kim DW, Shin HJ, et al. Association between dietary acid load and the risk of cardiovascular disease: nationwide surveys (KNHANES 20082011). Cardiovasc Diabetol. 2016;15:122. doi: 10.1186/ s12933-016-0436-z.

17. Xu H, Jia T, Huang X, Risérus $U$, Cederholm T, Arnlöv J, et al. Dietary acid load, insulin sensitivity and risk of type 2 diabetes in community-dwelling older men. Diabetologia. 2014;57:1561-8. doi: 10.1007/s00125-014-3275-z.

18. Gæde J, Nielsen T, Madsen ML, Toft U, Jørgensen T, Overvad $\mathrm{K}$, et al. Population-based studies of relationships between dietary acidity load, insulin resistance and incident diabetes in Danes. Nutr J. 2018;17:91. doi: 10.1186/s12937-018-0395-1.

19. Akter S, Eguchi M, Kuwahara K, Kochi T, Ito R, Kurotani K, et al. High dietary acid load is associated with insulin resistance: The Furukawa Nutrition and Health Study. Clin Nutr. 2016;35:453459. doi: 10.1016/j.clnu.2015.03.008.

20. Scialla JJ, Anderson CA. Dietary acid load: a novel nutritional target in chronic kidney disease? Adv Chronic Kidney Dis. 2013;20:141-9. doi: 10.1053/j.ackd.2012.11.001.

21. Akter S, Kurotani K, Kashino I, Goto A, Mizoue T, Noda M, et al. High Dietary Acid Load Score Is Associated with Increased Risk of Type 2 Diabetes in Japanese Men: The Japan Public Health Center-based Prospective Study. J Nutr. 2016;146:107683. doi: 10.3945/jn.115.225177. 